\title{
PENGARUH KREDIT USAHA RAKYAT TERHADAP PROFITABILITAS UMKM DI KABUPATEN PARIGI MOUTONG
}

\author{
I Kadek Adi Aribawo \\ Muh. Faisal \\ Husnah \\ Program Studi Manajemen, Fakultas Ekonomi, Universitas Tadulako \\ Email: ikadekadiaribawo@gmail.com, faisal@gmail.com, husnahatjo@yahoo.co.id . \\ ABSTRACT
}

Research objectives, (1) To analyze the impact of entrepreneurship quality on the effectiveness of KUR in increasing profitability (2) Analyzing the impact of business scale on the effectiveness of KUR in increasing profitability. (3) Analyzing the profitability level of UMKM with Micro KUR. (4) Analyze the profitability level of UMKM with Retail KUR. (5) Analyze the level of profitability of UMKM simultaneously with Micro KUR and Retail KUR.

The results of the study, (1) The absence of a relationship between profitability and the experience of entrepreneurs managing small businesses, because experience does not improve the entrepreneurial innovation competence. (2) Hasi refers to the consistency of the relationship between size or business scale and profitability. (3) The significance value of 0.903> 0.05 can be concluded that Micro KUR does not affect the profitability of UMKM in Parigi Moutong Regency. (4) It is known that the significance value is 0.039 $<0.05$ so that it is concluded that Retail KUR influences the profitability of UMKM in Parigi Moutong Regency. (5) Given the significance value of 0.106>0.05 it can be concluded that the KUR Fund does not affect the profitability of UMKM in Parigi Moutong Regency.

Keywords: Entrepreneur Quality, Business Scale, Business Size, KUR, Profitability.

\section{ABSTRAK}

Tujuan penelitian, (1) Menganlisis dampak kualitas enterpreneur terhadap efektivitas KUR dalam meningkatkan profitabilitas.(2) Menganlisis dampak skala usaha terhadap efektivitas KUR dalam meningkatkan profitabilitas. (3) Menganalisis tingkat profitabilitas UMKM dengan KUR Mikro. (4) Menganalisis tingkat profitabilitas UMKM dengan KUR Ritel.(5) Menganalisis tingkat profitabilitas UMKM secara simultan dengan KUR Mikro dan KUR Ritel.

Hasil penelitian, (1) Tidak adanya hubungan antara profitabilitas dengan pengalaman enterpreneur mengelola usaha kecil, karena pengalaman tidak meningkatkan kompetensi inovasi seorang enterpreneur. (2) Hasi memenujukan konsistensi hubungan antara size atau skala usaha dengan profitabilitas. (3) Diketahui nilai signifikansi sebesar 0,903 > 0,05 dapat disimpulkan bahwa KUR Mikro tidak berpengaruh terhadap Profitabilitas UMKM di Kabupaten Parigi Moutong. (4) Diketahui nilai signifikansi sebesar 0,039<0,05 sehinga disimpulkan bahwa KUR Ritel berpengaruh terhadap Profitabilitas UMKM di Kabupaten Parigi Moutong. (5) Diketahui nilai signifikansi sebesar 0,106 > 0,05 dapat disimpulkan bahwa Dana KUR tidak berpengaruh terhadap Profitabilitas UMKM di Kabupaten Parigi Moutong.

Kata kunci: Kualitas Entrepreneur, Skala Usaha, Size Usaha, KUR, Profitabilitas.

\section{PENDAHULUAN}

Program KUR lahir sebagai respon dari Instruksi Presiden No. 6 Tahun 2007 Tentang Kebijakan Percepatan Pengembangan Sektor Riil dan Pemberdayaan Usaha Mikro, Kecil, dan Menengah khususnya bidang Reformasi Sektor Keuangan. Melalui program KUR, pemerintah mengharapkan adanya akselerasi/percepatan pengembangan kegiatan perekonomian terutama di sektor riil, dalam rangka penanggulangan kemiskinan dan perluasan kesempatan kerja.

Suhardjono (2003:33) ada dua definisi usaha kecil yang dikenal di Indonesia. Pertama, usaha kecil menurut Undang-undang Nomor 9 tahun 1995 dan surat edaran Bank Indonesia No. 3/9/Bkr tahun 2001 tentang usaha kecil adalah kegiatan ekonomi rakyat yang memiliki hasil penjualan tahunan maksimal $\mathrm{Rp}$ 1 miliar dan memiliki kekayaan bersih, tidak termasuk tanah dan bangunan dan tempat usaha, paling banyak Rp200 juta. Kedua, menurut kategori Biro Pusat Statistik (BPS), usaha kecil identik dengan industri kecil dan industri rumah tangga. Biro Pusat Statistik (BPS) mengidentikan usaha kecil dengan industri rumah tangga, dengan klasifikasi sebagai berikut: (1) Industri rumah tangga dengan pekerja 1-4 orang, (2) Industri kecil dengan pekerja 5-19 orang, (3) Industri menengah dengan pekerja 20-99 orang, 
dan (4) Industri besar dengan pekerja 100 orang atau lebih. Mengacu pada pendapat dan kriteria di atas, dapat disimpulkan bahwa usaha kecil merupakan usaha rakyat skala kecil, sebagaimana dapat diukur berdasarkan aset bersih, omset penjualan dan jumlah tenaga kerja.

Usaha kecil dari sudut pandang ilmu keuangan dikaitkan dengan masalah informasi yang berkonsekuensi terhadap sumber keuangan. Dalam Berger dan Udell (1998), keuangan bisnis kecil dikarakteristikan sebagai informational opacity atau secara informasi tidak transparan. Hal ini karena dalam operasional bisnis kecil, kontrak tidak terpublikasi, laporan keuangan tidak teraudit, dan tidak menerbitkan surat berharga yang diperdagangkan dan dinilai publik. Keuangan yang tidak transparan mengakibatkan usaha kecil tidak dapat memperoleh dana di pasar publik melalui emisi saham dan obligasi. Sebagai alternatif, usaha kecil berusaha memperoleh dana di pasar private untuk pembiayaan bisnis, melalui ekuitas private (modal pemilik, angel, ventura, dll) dan hutang private (bank, perusahaan finance, kredit dagang, dll).

\section{Gambar 1 \\ Data Jumlah Nominal dan Rekening Penerima KUR Di Kabupaten Parigi Moutong Tahun 2014 - 2016}

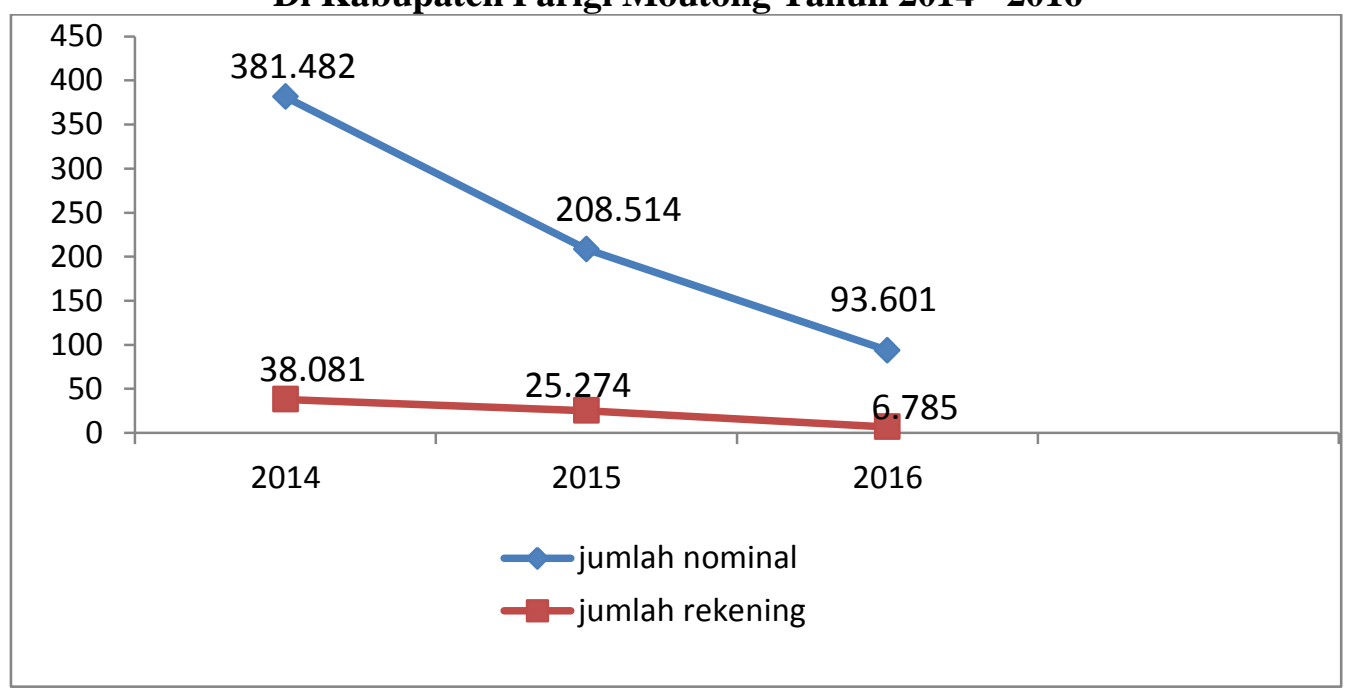

Sumber: Bank Indonesia (BI) Juli 2017.

Suku bunga rendah dan penjaminan meningkatkan akses UMKM terhadap dana KUR, walaupun demikian jumlah dana KUR yang disalurkan mengalami penurunan dari tahun ke tahun. Kredit Usaha Rakyat (KUR) adalah pembiayaan yang diberikan oleh perbankan kepada usaha kecil yang memiliki prospek bisnis yang baik atau feasible tapi belum bankable. Dana KUR digunakan untuk modal kerja dan investasi yang hasilnya disamping untuk pengembangan usaha juga untuk mengembalikan pinjaman. Usaha kecil feasible adalah usaha berkualitas dalam model Ross (1977), sehingga keputusan meminjam KUR merupakan signal bahwa usaha adalah profitabel, sehingga profitabilitas akan meningkat setelah menerima dana KUR.

Karakteristik informational opacity atau tidak transparan pada keuangan usaha kecil merupakan penyebab mengapa usaha kecil sulit memperoleh pembiayaan (Berger dan Udell 1998). Akan tetapi, menurut Diamond (1984), perantara keuangan (intermediar) yang berfungsi sebagai delegated monitors atas nama investor mampu memproduksi informasi secara efisien, sehingga pembiayaan usaha kecil yang tidak transparan melalui pasar private bisa dilakukan. Informasi yang dihasilkan terdiri dari informasi usaha dan kualitas enterpreneur. Semakin prospektif usaha dan semakin berkualitas enterpreneur semakin besar peluang untuk memperoleh kredit bank. Perusahaan yang memiliki hubungan relatif lama dengan kreditor berpeluang untuk memperoleh kredit bank.

Pemberian kredit, bank menerapkan syarat jaminan agar kredit digunakan untuk meningkatkan profitabilitas. Sebagaimana dalam Berger dan Udell (1998), syarat jaminan yang harus dipenuhi oleh bisnis kecil yang tidak transparan dimaksudkan untuk mengatasi masalah adverse selection (karena pinjaman awal tidak cukup) dan moral hazard (setelah kredit diberikan). Hal ini berarti bahwa ketersediaan aset menentukan kelayakan kredit yang akan digunakan untuk pengembangan usaha. Berdasarkan uraian pada latar belakang di atas, masalah penelitian ini adalah : (1) Apakah kualitas enterpreneur berdampak terhadap efektifitas pemanfaatan KUR dalam meningkatkan profitabilitas UMKM di Kabupaten Parigi Moutong.? (2) Apakah skala usaha berdampak terhadap evektifitas 
pemanfaatan KUR dalam meningkatkan profitabilitas UMKM di Kabupaten Parigi Moutong.? (3) Apakah terdapat pengaruh KUR Mikro terhadap profitabilitas pada UMKM di Kabupaten Parigi Moutong.? (4) Apakah Terdapat Pengaruh KUR Ritel terhadap profitabilitas pada UMKM di Kabupaten Parigi Moutong.? (5) Apakah Terdapat Pengaruh KUR Mikro dan KUR Ritel secara simultan terhadap profitabilitas pada UMKM di Kabupaten Parigi Moutong.?

Berdasarkan permasalahan penelitian, tujuan dari penelitian ini dilaksanakan adalah sebagai berikut : (1) Untuk menganlisis dampak kualitas enterpreneur terhadap efektivitas pemanfatan KUR dalam meningkatkan profitabilitas. (2) Untuk menganlisis dampak skala usaha terhadap efektivitas pemanfatan KUR dalam meningkatkan profitabilitas. (3) Untuk menganalisis tingkat profitabilitas UMKM dengan mengunakan KUR Mikro. (4) Untuk menganalisis tingkat profitabilitas UMKM dengan mengunakan KUR Ritel. (5) Untuk menganalisis tingkat profitabilitas UMKM secara simultan dengan mengunakan KUR Mikro dan KUR Ritel..

\section{KAJIAN LITERATURE DAN PENGEMBANGAN HIPOTESIS}

Usaha kecil tersebar di sektor-sektor ekonomi dan memiliki aktivitas beragam di bidang produksi, distribusi dan jasa. Menurut Tohar (2009), usaha kecil adalah kegiatan ekonomi rakyat yang berskala kecil, dan memenuhi kekayaan bersih atau hasil penjualan tahunan serta kepemilikan sebagaimana diatur dalam undang-undang. Kriteria usaha kecil menurut UU No. 20 Tahun 2008 adalah: (1) Memiliki kekayaan bersih lebih dari Rp.50 juta hingga Rp. 500 juta tidak termasuk tanah dan bangunan tempat usaha; dan (2) Memiliki hasil penjualan tahunan lebih dari Rp.300 juta hingga Rp. 2,5 milyar.

Biro Pusat Statistik (BPS) mengidentikan usaha kecil dengan industri rumah tangga, dengan klasifikasi sebagai berikut: (1) Industri rumah tangga dengan pekerja 1-4 orang, (2) Industri kecil dengan pekerja 519 orang, (3) Industri menengah dengan pekerja 20-99 orang, dan (4) Industri besar dengan pekerja 100 orang atau lebih. Mengacu pada pendapat dan kriteria di atas, dapat disimpulkan bahwa usaha kecil merupakan usaha rakyat skala kecil, sebagaimana dapat diukur berdasarkan aset bersih, omset penjualan dan jumlah tenaga kerja.

Usaha kecil dari sudut pandang ilmu keuangan dikaitkan dengan masalah informasi yang berkonsekuensi terhadap sumber keuangan. Berger dan Udell (1998), keuangan bisnis kecil dikarakteristikan sebagai informational opacity atau secara informasi tidak transparan. Hal ini karena dalam operasional bisnis kecil, kontrak tidak terpublikasi, laporan keuangan tidak teraudit, dan tidak menerbitkan surat berharga yang diperdagangkan dan dinilai publik. Keuangan yang tidak transparan mengakibatkan usaha kecil tidak dapat memperoleh dana di pasar publik melalui emisi saham dan obligasi. Sebagai alternatif, usaha kecil berusaha memperoleh dana di pasar private untuk pembiayaan bisnis, melalui ekuitas private (modal pemilik, angel, ventura) dan hutang private (bank, perusahaan finance, kredit dagang).

Majluf (1984) pada model pembiayaan hirarki, dimana perusahaan menggunakan pertama pembiayaan internal dan jika dana internal habis terpakai barulah perusahaan melakukan emisi hutang, dan alternatif terakhir adalah emisi saham. Model ini memberikan implikasi bahwa hutang dan profitabilitas berhubungan secara negatif.

Lama usaha dapat mempengaruhi tingkat pendapatan, lamanya seorang pelaku usaha atau bisnis menekuni bidang usahanya akan mempengaruhi produktivitasnya (kemampuan/keahliannya), sehingga dapat menambah efisiensi dan mampu menekan biaya produksi lebih kecil dari pada hasil penjualan. Semakin lama menekuni bidang usaha perdagangan akan makin meningkatkan pengetahuan tentang selera ataupun perilaku konsumen. Keterampilan berdagang makin bertambah dan semakin banyak pula relasi bisnis maupun pelanggan yang berhasil di jaring (Wicaksono, 2011).

Menurut (Nicholls dan Hollmes dalam Nirmala 2011) skala usaha merupakan kemampuan perusahaan dalam mengelolah usahanya dengan melihat jumlah karyawannya yang dipekerjakannya dan berapa besar pendapatan yang diperoleh perusahaan dalam satu periode akuntansi. Untuk menentukan seberapa besar skala usaha dapat dilihat dari total asset yang dimiliki usaha kecil, dimana semakin banyak total aset maka aset dalam kasus ini bank sebagai penyedia modal mensyaratkan total aset sebagai jaminan. Jaminan tersebut akan mengatasi masalaha adverse selection dan moral hazard.

Kredit Usaha Rakyat (KUR) adalah pembiayaan yang diberikan oleh perbankan kepada usaha kecil yang memiliki prospek bisnis yang baik atau feasible tapi belum bankable. Dana KUR digunakan untuk modal kerja dan investasi yang hasilnya disamping untuk pengembangan usaha juga untuk mengembalikan pinjaman. Usaha kecil feasible adalah usaha berkualitas dalam model Ross (1977), sehingga keputusan meminjam KUR merupakan signal bahwa usaha adalah profitabel, sehingga profitabilitas akan meningkat setelah menerima dana KUR. 
Karakteristik informational opacity atau tidak transparan pada keuangan usaha kecil merupakan penyebab mengapa usaha kecil sulit memperoleh pembiayaan (Berger dan Udell 1998). Akan tetapi, menurut Diamond (1984), perantara keuangan (intermediar) yang berfungsi sebagai delegated monitors atas nama investor mampu memproduksi informasi secara efisien, sehingga pembiayaan usaha kecil yang tidak transparan melalui pasar private bisa dilakukan. Informasi yang dihasilkan terdiri dari informasi usaha dan kualitas enterpreneur. Semakin prospektif usaha dan semakin berkualitas enterpreneur semakin besar peluang untuk memperoleh kredit bank. Perusahaan yang memiliki hubungan relatif lama dengan kreditor berpeluang untuk memperoleh kredit bank.

Pemberian kredit, bank menerapkan syarat jaminan agar kredit digunakan untuk meningkatkan profitabilitas. Sebagaimana dalam Berger dan Udell (1998), syarat jaminan yang harus dipenuhi oleh bisnis kecil yang tidak transparan dimaksudkan untuk mengatasi masalah adverse selection (karena pinjaman awal tidak cukup) dan moral hazard (setelah kredit diberikan). Hal ini berarti bahwa ketersediaan aset menentukan kelayakan kredit yang akan digunakan untuk pengembangan usaha. Kerangka pikir penelitian dirangkum dalam gambar 2.

Gambar 2

Kerangka Pikir Penelitian

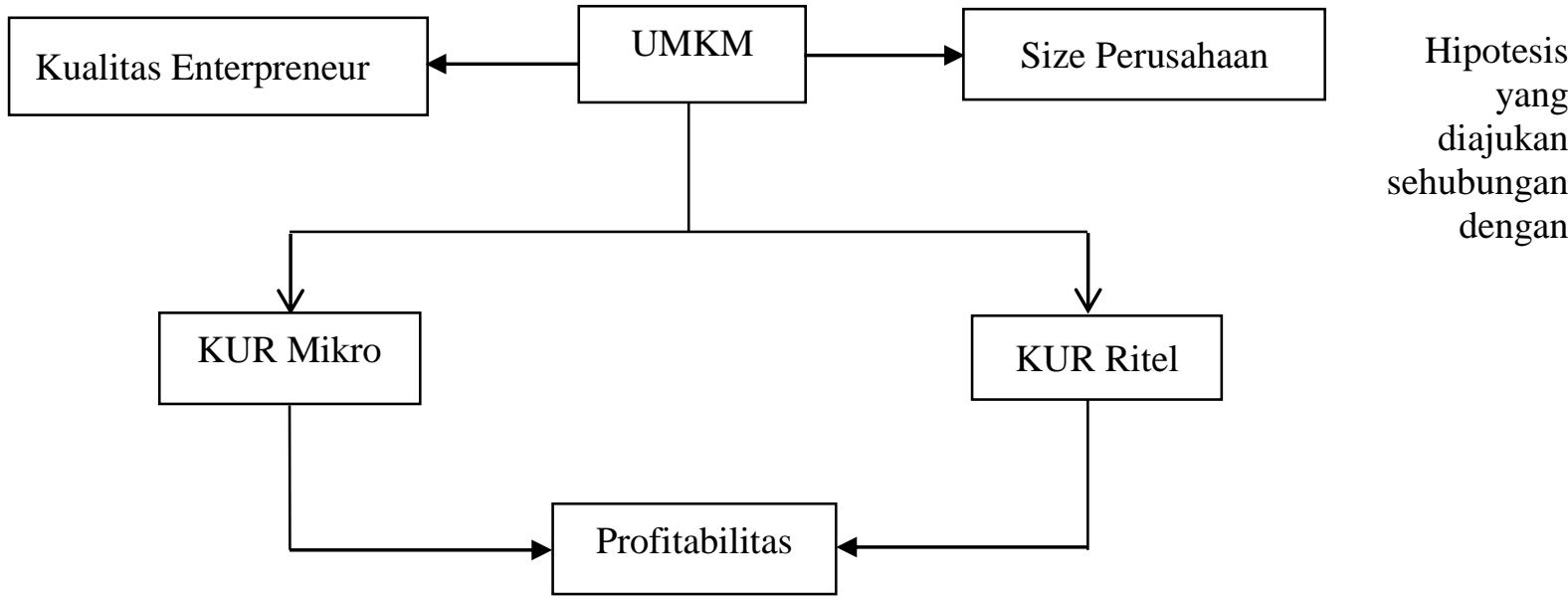

permasalahan penelitian adalah sebagai berikut:

H1 : Bahwa terdapat pengaruh KUR Mikro terhadap profitabilitas pada UMKM di Kabupaten Parigi Moutong.

H2 : Bahwa terdapat pengaruh KUR Ritel terhadap profitabilitas pada UMKM di Kabupaten Parigi Moutong.

H3 : Bahwa terdapat pengaruh KUR Mikro dan KUR Ritel secara simultan (bersama-sama) terhadap profitabilitas pada UMKM di Kabupaten Parigi Moutong.

\section{METODE PENELITIAN}

Jenis penelitian ini adalah penelitian Deskriptif dan Hipotesis. Yang tujuannya adalah untuk mengetahui secara jelas apakah kualitas entrepreneur dan skala usaha UMKM dalam pemberian dana KUR dapat meningkatkan profitabilitas, dan menguji apakah pemberian KUR berpengaruh terhadap profitabilitas pada UMKM di Kabupaten Parigi Moutong.

Adapun variabel yang digunakan dalam penelitian ini terdiri dari variabel independen (bebas) dan variabel dependen (terikat). Operasional variabel dalam penelitian ini dapat dilihat pada tabel 1 sebagai berikut:

Table 1

Operasional Variabel

\begin{tabular}{|l|l|l|l|l|}
\hline Variabel & Dimensi & \multicolumn{1}{|c|}{ Definisi } & Indikator & Skala \\
\hline ofitabilitas & $\begin{array}{l}\text { trun On Aset } \\
\text { (ROA) }\end{array}$ & $\begin{array}{l}\text { ofitabilitas mengambarkan } \\
\text { kemampuan perusahaan } \\
\text { memperoleh laba sebagai hasil } \\
\text { dari pengelolaan aset. }\end{array}$ & RoA $=\frac{\text { Laba } \text { bersih }}{\text { Total } \text { Aset }} \times \mathbf{~ 1 0 0 \% ~}$ & Rasio \\
\hline ana KUR & KUR Mikro & nis pinjaman yang diberikan & Penyaluran KUR Mikro & Interval \\
\hline
\end{tabular}




\begin{tabular}{|c|c|c|c|c|}
\hline & & $\begin{array}{l}\text { kepada penerima KUR dengan } \\
\text { jumlah paling banyak sebesar } \\
\text { Rp25.000.000, Suku bunga } \\
\text { KUR Mikro sebesar } 12 \% \\
\text { efektif pertahun } \\
\text { disesuaikan dengan suku } \\
\text { bunga flat/anuitas yang setara. }\end{array}$ & & \\
\hline & KUR Ritel & $\begin{array}{l}\text { Jenis pinjaman yang diberikan } \\
\text { kepada pengusaha kelas mikro, } \\
\text { kecil dan menengah dengan } \\
\text { penerimaan dana KUR } \\
\text { sejumlah diatas Rp25.000.000 } \\
\text { dan paling banyak sebesar } \\
\text { Rp500.000.000, Suku bunga } \\
\text { KUR Mikro sebesar } 12 \% \\
\text { efektif pertahun }\end{array}$ & Penyaluran KUR Ritel & Interval \\
\hline $\begin{array}{l}\text { Kualitas } \\
\text { Enterpreneur }\end{array}$ & $\begin{array}{l}\text { Manajemen } \\
\text { Dana KUR }\end{array}$ & $\begin{array}{lr}\text { Semakin baik } & \text { kualitas } \\
\text { enterpreneur semakin } & \text { tinggi } \\
\text { kemampuannya } & \text { dalam } \\
\text { memanfaatkan dana } & \text { KUR } \\
\text { untuk operasional dan } & \text { dan } \\
\text { investasi, sehingga usaha kecil } \\
\text { memperoleh profitabilitas yang } \\
\text { tinggi. }\end{array}$ & \begin{tabular}{|l} 
- \\
Pingkat Pendidikan \\
Pengelola UMKM \\
Pengalaman \\
entrepreneur
\end{tabular} & Interval \\
\hline Skala Usaha & $\begin{array}{l}\text { Jumlah Dana } \\
\text { KUR }\end{array}$ & $\begin{array}{l}\text { Skala usaha atau size } \\
\text { menggambarkan kemampuan } \\
\text { usaha kecil menyediakan } \\
\text { jaminan atas kredit yang akan } \\
\text { diterima. Dalam kasus dimana } \\
\text { bank mensyaratkan jaminan, } \\
\text { maka jaminan dapat mengatasi } \\
\text { masalah adverse selection dan } \\
\text { moral hazard, sehingga dana } \\
\text { KUR dapat dikelola dengan } \\
\text { baik dan menghasilkan } \\
\text { profitabilitas. }\end{array}$ & Total Asset & ntervall \\
\hline
\end{tabular}

Metode analisis data yang dipergunakan dalam penelitian ini, sebagai berikut:

\section{Analisa deskriptif}

Analisis deskriptif merupakan analisis yang paling mendasar untuk menggambarkan keadaan data secara umum. Analisis deskriptif ini meliputi beberapa hal, yakni distribusi frekuensi, pengukuran tendensi pusat, dan pengukuran variabilitas. Untuk analisis deskriptif, data-data disajikan dalam bentuk tabel, diagram, grafik, dan lain-lain. Hal ini ditujukan untuk mempermudah memahami data-data yang disajikan. Menurut ilmu perencanaan, penggunaan statistik deskriptif dapat dilakukan untuk mempermudah penyampaian informasi agar mudah diterima dan dipahami. Untuk penelitian ini Analisa deskriptif dilakukan dengan cara mengelompokan tingkat profitabilitas berdasarkan interval kelas atau kelompok dalam setiap variabel yang dipertimbangkan. Analisa dibantu dengan tabel frekuensi dan metode statistik deskriptif (rata-rata). Profitabilitas menggambarkan kemampuan perusahaan memperoleh laba sebagai hasil dari pengelolaan aset. profitabilitas merupakan hasil dari investasi dimana terdapat porsi dana KUR dalam investasi. Oleh karenanya, semakin besar dana KUR, semakin besar investasi dan semakin tinggi profitabilitas usaha kecil. Profitabilitas diukur dengan rasio laba bersih sesudah pajak terhadap total asset.

$$
\text { Profitabilitas }=\frac{\text { Laba Bersih Sesudah Pajak }}{\text { Total Aset }} \times 100 \%
$$




\section{Uji Asumsi Klasik}

Untuk melakukan analisis data kuantitatif seringkali kita menggunakan uji persyaratan analisis. Uji analisis untuk Regresi Berganda yang juga sering disebut dengan istilah Uji Asumsi Klasik. Agar model regresi tidak bias atau agar model regresi BLUE (Best Linear Unbiased Estimator) maka perlu dilakukan uji asumsi klasik terlebih dahulu. Uji persyaratan analisis untuk regresi berganda yang sering digunakan adalah sebagai berikut: (1) Uji normalitas dimaksudkan untuk mengetahui apakah data berdistribusi normal atau tidak berdistribusi normal. Dalam penelitian ini uji normalitas dilakukan dengan mengamati penyebaran data pada sumbu diagonal suatu grafik. (2) Uji Linieritas digunakan untuk mendeteksi adanya hubungan linier antara variabel $\mathrm{X}$ dan $\mathrm{Y}$ yang bisa dilakukan, sebagai berikut : (a) Plot antara residu versus Y-topi. Jika plot yang bersangkutan menggambarkan suatu scatter diagram (diagram pencar) dalam arti tidak berpola maka dapat dikatakan tidak terjadi mispesifikasi pada fungsi regresi, hal ini bararti bahwa hubungan antara variabal $\mathrm{X}$ dan $\mathrm{Y}$ adalah linier. (b) Plot antara variabel $\mathrm{X}$ versus $\mathrm{Y}$. Jika plot menggambarkan garis lurus maka asumsi pertama ini telah terpenuhi. (c) Plot antara residu versus X. Jika plot menggambarkan diagram pencar maka linieritas ini sudah terpenuhi. (3) Uji Autokorelasi adalah sebuah analisis statistik yang dilakukan untuk mengetahui adakah korelasi variabel yang ada di dalam model prediksi dengan perubahan waktu. Oleh karena itu, apabila asumsi autokorelasi terjadi pada sebuah model prediksi, maka nilai disturbance tidak lagi berpasangan secara bebas, melainkan berpasangan secara autokorelasi. (4) Uji multikolinearitas adalah uji yang dilakukan untuk memastikan apakah di dalam sebuah model regresi ada interkorelasi atau kolinearitas antar variabel bebas. Interkorelasi adalah hubungan yang linear atau hubungan yang kuat antara satu variabel bebas atau variabel prediktor dengan variabel prediktor lainnya di dalam sebuah model regresi. (5) Uji heteroskedastisitas digunakan untuk mengetahui ada atau tidaknya penyimpangan asumsi klasik heteroskedastisitas yaitu adanya ketidaksamaan varian dari residual untuk semua pengamatan pada model regresi. Prasyarat yang harus terpenuhi dalam model regresi adalah tidak adanya gejala heteroskedastisitas.

\section{Uji Regresi Linear Berganda}

Analisis regresi linier berganda adalah hubungan secara linear antara dua atau lebih variabel independen $(\mathrm{X} 1, \mathrm{X} 2, \ldots . \mathrm{Xn})$ dengan variabel dependen $(\mathrm{Y})$. Analisis ini untuk mengetahui arah hubungan antara variabel independen dengan variabel dependen apakah masing-masing variabel independen berhubungan positif atau negatif dan untuk memprediksi nilai dari variabel dependen apabila nilai variabel independen mengalami kenaikan atau penurunan. Data yang digunakan biasanya berskala interval atau rasio.

Persamaan regresi linear berganda sebagai berikut:

$\mathrm{Y}^{\prime}=\mathrm{a}+\mathrm{b} 1 \mathrm{X} 1+\mathrm{b} 2 \mathrm{X} 2+\ldots . .+\mathrm{bnXn}$

Keterangan:

Y' $\quad=$ Variabel dependen (nilai yang diprediksikan)

$\mathrm{X} 1$ dan $\mathrm{X} 2=$ Variabel independen

a $\quad=$ Konstanta (nilai $Y^{\prime}$ apabila X1, X2 ....Xn $=0$ )

$\mathrm{b} \quad=$ Koefisien regresi (nilai peningkatan ataupun penurunan)

Untuk menguji tingkat profitabilitas usaha kecil secara simultan dan persial dengan menggunakan KUR Mikro dan KUR Ritel dilakukan analisis regresi linear berganda, sehingga dapat dilakukan uju t dan uji F, dimana uji t untuk mengetahui ada atu tidaknya pengaruh secara parsial (sendiri) yang diberikan variabel KUR mikro dan KUR ritel terhadap variabel profitabilitas. Uji $\mathrm{F}$ bertujuan untuk mengetahui ada atau tidaknya pengaruh secara simultan (bersama-sama) yang diberikan variabel KUR mikro dan KUR ritel terhadap variabel Profitabilitas.

\section{HASIL DAN PEMBAHASAN}

\section{Tabel 1}

Karakteristik UMKM Sampel

\begin{tabular}{|c|c|c|c|}
\hline No & Uraian & Jumlah Usaha Kecil & Persentase \\
\hline \multicolumn{4}{|c|}{ Bagian A: Sektor Aktivitas } \\
\hline 1 & Bidang perdagangan & 40 & $66.6 \%$ \\
\hline 2 & Bidang jasa & 6 & $10 \%$ \\
\hline
\end{tabular}




\begin{tabular}{|c|c|c|c|}
\hline 3 & Bidang Restoran & 10 & $16.7 \%$ \\
\hline 4 & Bidang Peternakan & 3 & $5 \%$ \\
\hline 5 & Bidang Pertanian & 1 & $1.7 \%$ \\
\hline & Jumlah & 60 & $100 \%$ \\
\hline \multicolumn{4}{|c|}{ Bagian B: Lokasi } \\
\hline 1 & Ampibabo & 10 & $16.7 \%$ \\
\hline 2 & Parigi & 16 & $26.6 \%$ \\
\hline 3 & Parigi Selatan & 10 & $16.7 \%$ \\
\hline No & Uraian & Jumlah Usaha Kecil & Persentase \\
\hline 4 & Parigi Tengah & 7 & $11.7 \%$ \\
\hline 5 & Parigi Utara & 7 & $11.7 \%$ \\
\hline 6 & Parigi Barat & 5 & $8.3 \%$ \\
\hline 7 & Kecamatan Torue & 5 & $8.3 \%$ \\
\hline & Jumlah & 60 & $100 \%$ \\
\hline \multicolumn{4}{|c|}{ Bagian C: Tenaga Kerja } \\
\hline 1 & 0 & 30 & $50 \%$ \\
\hline 2 & $1-5$ & 27 & $45 \%$ \\
\hline 3 & $6-7$ & 3 & $5 \%$ \\
\hline \multicolumn{2}{|r|}{ Jumlah } & 60 & $100 \%$ \\
\hline \multicolumn{4}{|c|}{ Bagian D: Lama Usaha (tahun) } \\
\hline 1 & $<4$ & 27 & $45 \%$ \\
\hline 2 & $5-7$ & 19 & $31,7 \%$ \\
\hline \multicolumn{4}{|c|}{ Bagian D: Lama Usaha (tahun) } \\
\hline 3 & $8-10$ & 8 & $13,3 \%$ \\
\hline 4 & $>11$ & 6 & $10 \%$ \\
\hline \multicolumn{2}{|r|}{ Jumlah } & 60 & $100 \%$ \\
\hline
\end{tabular}

Sumber: Data Primer diolah, (Oktober, 2017)

Terlihat pada tabel 1 Panel A, sebanyak 40 usaha kecil sampel atau 66,6\% memiliki aktivitas di sektor perdagangan dan 6 usaha di sektor jasa. Sampel penelitian tersebar di seluruh wilayah administratif Kabupaten Parigi, dimana sebanyak 16 usaha berlokasi di Parigi Kota, 10 usaha di Parigi Selatan, 7 usaha di Parigi Utara dan Parigi Tengah. Sebagian besar atau 30 usaha kecil dalam sampel tidak memiliki tenaga kerja, dan hanya 3 usaha kecil yang memiliki tenaga kerja 6-10 orang. Sampel penelitian mencakup sebagian besar usaha kecil yang memiliki lama usaha dibawah 4 tahun. Karakteristik lain disampaikan pada tabel 2.

Tabel 2

Usia, Jenis Kelamin, Tingkat Pendidikan Pengelola Usaha Kecil Sampel

\begin{tabular}{|c|c|c|c|}
\hline No & Uraian & Jumlah Usaha Kecil & Persentase \\
\hline \multicolumn{4}{|c|}{ Panel A: Usia Pengelola Usaha (tahun) } \\
\hline 1 & $20-29$ & 9 & 15 \\
\hline 2 & $30-39$ & 18 & 30 \\
\hline 3 & $40-49$ & 17 & 28.3 \\
\hline 4 & $50-59$ & 14 & 23.3 \\
\hline 5 & $>60$ & 2 & 3.4 \\
\hline \multicolumn{2}{|c|}{ Jumlah } & 60 & 100 \\
\hline \multicolumn{4}{|c|}{ Panel B: Jenis Kelamin } \\
\hline 1 & Laki-laki & 28 & 46.7 \\
\hline 2 & Perempuan & 32 & 53.3 \\
\hline \multicolumn{2}{|c|}{ Jumlah } & 60 & 100 \\
\hline \multicolumn{4}{|c|}{ Panel C: Tngat Pendidikan Pengelola } \\
\hline 1 & Tidak sekolah & 3 & 5 \\
\hline 2 & SD & 14 & 11.7 \\
\hline 3 & SMP & 13 & 33.3 \\
\hline 4 & SMA & 21 & 35 \\
\hline
\end{tabular}




\begin{tabular}{|c|c|c|c|}
\hline 5 & D3/S1 & 9 & 15 \\
\hline Jumlah & $\mathbf{6 0}$ & $\mathbf{1 0 0}$ \\
\hline
\end{tabular}

Sumber: Data Primer diolah, (Oktober, 2017)

Sebagaimana pada tabel 2 Panel A, usia pengelola usaha kecil sampel terkonsentrasi pada kelompok umur 30-59 tahun, dengan komposisi hampir berimbang antara responden laki-laki dan perempuan. Sampel penelitian didominasi oleh pengelola yang memiliki tingkat pendidikan SD, SMP dan SMA.

Tabel 3

Profitabilitas Usaha Kecil Berdasarkan Tingkat Pendidikan

\begin{tabular}{|c|l|c|c|c|c|}
\hline No & \multicolumn{1}{|c|}{ Pendidikan } & N & $\begin{array}{c}\text { Rata-Rata } \\
\text { Aset }\end{array}$ & $\begin{array}{c}\text { Rata-Rata } \\
\text { Hutang KUR }\end{array}$ & $\begin{array}{c}\text { Rata-Rata } \\
\text { Profitabilitas }\end{array}$ \\
\hline 1 & Tidak Sekolah & 3 & $230,000,000$ & $51,333,333$ & 0,06 \\
\hline 2 & SD & 14 & $452,535,714$ & $70,285,714$ & 0,08 \\
\hline 3 & SMP & 13 & $487,384,615$ & $72,076,923$ & 0,06 \\
\hline 4 & SMA & 21 & $412,000,000$ & $64,428,571$ & 0,07 \\
\hline 5 & D3/S1 & 9 & $454,611,111$ & $59,677,777$ & 0,09 \\
\hline \multicolumn{4}{|c|}{ Jumlah } & $\mathbf{6 0}$ & \\
\hline
\end{tabular}

Sumber: Data primer diolah (Oktober, 2017)

Aset usaha lebih besar pada usaha kecil yang dikelola oleh pemimpin yang memiliki pendidikan SMP, akan tetapi tingkat profitabilitas semakin kecil. Semakin tinggi tingkat pendidikan dan semakin kecil asset yang dimiliki, semakin tinggi asset semakin tinggi KUR yang diperoleh. Akan tetapi, hubungan antara tingkat pendidikan dengan profitabilitas tidak linear, karena profitabilitas meningkat dengan semakin rendahnya tingkat pendidikan pengelola usaha kecil pada level SD. Disamping pendidikan pengelola, pengalaman yang dapat diwakili oleh lama mengelola usaha dapat menggambarkan kualitas sumberdaya manusia. Data tentang profitabilitas berdasarkan lama mengelola usaha yang diolah dari kuesioner disajikan pada tabel 4.

Tabel 4

Profitabilitas Usaha Kecil Berdasarkan Lama Mengelola Usaha

\begin{tabular}{|c|c|c|c|c|c|}
\hline No & Lama Usaha & $\mathbf{N}$ & $\begin{array}{c}\text { Rata-Rata } \\
\text { Aset }\end{array}$ & $\begin{array}{c}\text { Rata-Rata } \\
\text { Hutang KUR }\end{array}$ & $\begin{array}{c}\text { Rata-Rata } \\
\text { Profitabilitas }\end{array}$ \\
\hline 1 & $<4$ & 27 & $454,907,407$ & $71,518,518$ & 0,08 \\
\hline 2 & $5-7$ & 19 & $415,052,631$ & $62,131,578$ & 0,06 \\
\hline 3 & $8-10$ & 8 & $445,750,000$ & $69,512,500$ & 0,09 \\
\hline 4 & $>11$ & 6 & $395,083,333$ & $65,416,666$ & 0,06 \\
\hline \multicolumn{2}{|r|}{ Jumlah } & 60 & & & \\
\hline
\end{tabular}

Sumber: Data primer diolah (Oktober, 2017)

Profitabilitas cenderung lebih tinggi dengan lama enterpreneur mengelola usaha dibawah 4 tahun, dan peningkatan profitabilitas semakin lambat ketika lama mengelola usaha lebih dari 11 tahun. Pada interval lama mengelola usaha 0-10 tahun, aset semakin kecil yang konsisten dengan tingkat profitabilitas yang semakin kecil. Jumlah KUR tidak konsisten dengan lama mengelola usaha dan tingkat profitabilitas semakin rendah dengan semakin lama pengalaman mengelola usaha. Oleh karena itu, pengalaman tidak konsisten dengan tingkat profitabilitas.

Size usaha sebagaimana diukur dengan total aset dapat menggambarkan kemampuan perusahaan dalam memanfaatkan peluang bisnis yang menguntungkan. Hal ini berarti bahwa semakin besar size perusahaan semakin tinggi profitabilitas. Data tentang hubungan antara size dengan profitabilitas disajikan pada tabel 5.

Tabel 5

Profitabilitas Usaha Kecil Berdasarkan Size Usaha

\begin{tabular}{|c|c|c|c|c|c|}
\hline No & $\begin{array}{c}\text { Total Aset } \\
\text { (juta rupiah) }\end{array}$ & N & $\begin{array}{c}\text { Rata-Rata } \\
\text { Omset }\end{array}$ & $\begin{array}{c}\text { Rata-Rata } \\
\text { Dana KUR }\end{array}$ & $\begin{array}{c}\text { Rata-Rata } \\
\text { Profitabilitas }\end{array}$ \\
\hline
\end{tabular}




\begin{tabular}{|r|l|c|c|r|c|}
\hline & & & Penjualan & & \\
\hline 1 & $<100$ & 24 & $34,416,666$ & $40,833,333$ & 0,04 \\
\hline 2 & $101-300$ & 25 & $81,280,000$ & $224,000,000$ & 0,09 \\
\hline 3 & $301-500$ & 9 & $129,555,555$ & $438,333,333$ & 0,09 \\
\hline 4 & $>500$ & 2 & $200,250,000$ & $250,000,000$ & 0,12 \\
\hline \multicolumn{2}{|l|}{ Jumlah } & $\mathbf{6 0}$ & \multicolumn{3}{|l}{} \\
\hline
\end{tabular}

Sumber: Data Primer diolah (Oktober, 2017)

Profitabilitas semakin besar pada kelas interval aset yang semakin besar atau aset dan profitabilitas memiliki hubungan berbanding lurus. Sebagaimana sebelumnya, KUR yang diterima oleh usaha kecil semakin besar dengan besarnya aset.

Tabel 6

Hasil Uji t

\begin{tabular}{|l|r|r|r|r|r|}
\hline \multirow{2}{*}{ Model } & \multicolumn{2}{|c|}{ Unstandardized Coefficients } & \multicolumn{1}{|c|}{ S.Coefficients } & \multirow{2}{*}{} \\
\cline { 2 - 4 } & \multicolumn{1}{|c|}{$\mathrm{B}$} & Std. Error & \multicolumn{1}{c|}{ Beta } & \multicolumn{1}{c|}{ T } & \multicolumn{1}{c|}{ Sig. } \\
\hline 1 (Constant) & 48101303.360 & 14532038.544 & & 3.310 & .003 \\
KUR mikro & .080 & .650 & .022 & .123 & .903 \\
KUR ritel & -.028 & .013 & -.396 & -2.174 & .039 \\
\hline
\end{tabular}

Sumber: Output SPSS, 2017

Perbandingan tingkat profitabilitas 30 usaha kecil memperoleh dana KUR Mikro dengan menggunakan metode uji t menghasilkan statistik $\mathrm{t}$ tes yang tidak signifikan. Oleh karena itu, KUR Mikro yang diterima oleh usaha kecil tidak berdampak terhadap tingkat profitabiltas UMKM di Kabupaten Parigi Moutong. Hasil ini nampaknya cukup konsisten dengan teori keuangan usaha kecil berbasis informasi.

Perbandingan tingkat profitabilitas 30 usaha kecil memperoleh dana KUR Ritel dengan menggunakan metode uji t menghasilkan statistik t tes yang signifikan. Oleh karena itu, Dana KUR yang diterima oleh usaha kecil berdampak terhadap tingkat profitabiltas pada UMKM di Kabupaten Parigi Moutong. Hasil ini sesuai dengan teori Hartono (2008), menyebutkan bahwa hutang itu mengandung resiko. Semakin tinggi risiko suatu perusahaan, semakin tinggi tingkat profitabilitas yang diharapkan sebagai imbalan terhadap tingginya risiko dan sebaliknya semakin rendah risiko perusahaan, semakin rendah tingkat profitabilitas yang diharapkan sebagai imbalan terhadap rendahnya risiko.

Tabel 7

Hasil Uji F

\begin{tabular}{|c|c|c|c|c|c|}
\hline Model & Sum of Squares & Df & Mean Square & $\mathrm{F}$ & Sig. \\
\hline $1 \quad$ Regression & 359528562531730.700 & 2 & 179764281265865.340 & 2.447 & $.106^{\mathrm{b}}$ \\
\hline Residual & 1983431854134936.000 & 27 & 73460439042034.670 & & \\
\hline Total & 2342960416666667.000 & 29 & & & \\
\hline
\end{tabular}

Sumber: Output SPSS, 2017

Perbandingan tingkat profitabilitas 60 usaha kecil memperoleh KUR dengan menggunakan metode uji $\mathrm{t}$ dan uji F menghasilkan statistik t tes yang tidak signifikan. Oleh karena itu, Dana KUR yang diterima oleh usaha kecil tidak berdampak terhadap tingkat profitabiltas pada UMKM di Kabupaten Parigi Moutong. Hasil ini nampaknya cukup konsisten dengan teori keuangan usaha kecil berbasis informasi.

Sebagaimana dalam Berger dan Udell (1998), usaha kecil dikarakteristikan sebagai informational opacity atau kekaburan informasi, dimana dalam situasi seperti ini sangat rawan terjadi moral hazard atau perilaku enterpreneur untuk mengalihkan dana pada proyek investasi yang lebih beresiko. Moral hazard nampaknya lebih akut pada kasus 60 usaha kecil di Kabupaten Parigi Moutong yang menjadi sampel penelitian ini. Informasi yang diperoleh dari lapangan bahwa relatif banyak dari enterpreneur menggunakan dana KUR yang belum sesuai dengan peruntukannya, misalnya untuk keperluan pribadi, sehingga menurunkan kinerja profitabilitas.

Moral hazard yang cukup akut tidak terlepas dari terbatasnya informasi tentang nasabah yang dimiliki oleh bank penyalur KUR. Kenyataannya, bank penyalur lebih menekankan pada jaminan dari pada reputasi nasabah, sehingga failit yang berkonsekuensi pada penyitaan aset jaminan lebih dipilih dari pada perlindungan nasabah. Realitas ini bertentangan dengan prediksi Damond (1984) bahwa fungsi bank sebagai 
delegated monitoring dapat memproduksi informasi secara efisien, yang memungkinkan pemberian hutang kepada bisnis kecil secara efisien.

Belum efektifnya KUR dalam meningkatkan profitabilitas usaha kecil juga dapat dikaitkan dengan fakta bahwa KUR yang diperoleh relatif kecil jika dibandingkan dengan peluang bisnis yang dimiliki oleh usaha kecil. Sebagaimana dalam model credit rationing yang dikembangkan oleh Stiglitz dan Weiss (1981), permintaan modal dan resiko borrower adalah fungsi dari interest rate, dimana interest rate tinggi meningkatkan permintaan modal dari borrower beresiko dan atau memberi borrower insentif untuk beralih ke investasi lebih berisiko. Karena resiko borrower meningkat dengan interest rate, maka optimal bagi lender untuk melakukan credit rationing (penjatahan kredit) dari pada meningkatkan interest rate untuk mengatasi asimetri informasi. Teori ini merupakan jawaban atas masalah keterbatasan kredit kepada bisnis kecil.

\section{KESIMPULAN DAN SARAN}

\section{Kesimpulan}

1. Analisis deskriptif yang dilakukan menunjukan tidak adanya hubungan antara profitabilitas dengan pengalaman enterpreneur mengelola UMKM, karena pengalaman tidak meningkatkan kompetensi inovasi seorang enterpreneur.

2. Analisis deskrptif selanjutnya memperlihatkan konsistensi hubungan antara size atau skala usaha dengan profitabilitas.

3. Diketahui nilai sig untuk pengaruh KUR Mikro terhadap Profitabilitas adalah sebesar 0,903>0,05 sehinga dapat disimpulkan bahwa dana KUR Mikro tidak berdapak pengaruh terhadap Profitabilitas UMKM di Kabupaten Parigi Moutong.

4. Diketahui nilai sig untuk pengaruh KUR Ritel terhadap Profitabilitas adalah sebesar $0,039<0,05$ sehinga dapat disimpulkan bahwa dana KUR Ritel berpengaruh terhadap Profitabilitas UMKM di Kabupaten Parigi Moutong.

5. Secara simultan menunjukan bahwa KUR tidak berdampak terhadap peningkatan profitabilitas. Diketahui nilai signifikansi untuk pengaruh KUR mikro dan KUR ritel secara simultan terhadap Profitabilitas adalah sebesar 0,106 > 0,05 sehinga Hasil ini dikaitkan dengan moral hazard yang dimana KUR tidak dimanfaatkan sesuai peruntukannya, bank penyalur tidak berfungsi sebagai delegated monitoring yang memproduksi informasi secara efisien, dan masalah keterbatasan kredit kepada bisnis kecil.

\section{Saran}

1. Diharapkan bank penyalur lebih terarah pada produksi informasi dalam rangka mereduksi moral hazard.

2. Bagi Dinas UMKM dan koperasi, diharapkan dapat memberdayakan usaha kecil dengan mengaitkan KUR dengan profitabilitas.

3. Bagi penerima KUR diharapkan mengunakan dana tersebut sesuai dengan peruntukan untuk mengembangn usaha.

4. Diharapkan rekomendasi yang diajukan oleh penulis akan membuat penerapan prinsip-prinsip anggaran berbasis kinerja menjadi lebih baik dan dapat menekan permasalahan-permasalahan yang mempengaruhi Profitabiltas UMKM di Kabupaten Parigi Moutong.

5. Disarankan untuk peneliti selanjutnya yang akan melakukan penelitian yang sama, diharapkan untuk lebih mendalam mengenai Penyaluran Dana KUR kepada UMKM agar dapat lebih meningkatkan profitabilitas UMKM sehingga hasil penelitiannya bisa lebih andal dan akurat daripada penelitian oleh penulis ini. Selain itu juga penelitian ini hanya dilakukan pada salah satu kabupaten di Provinsi Sulawesi Tengah yaitu Kabupaten Parigi Moutong. Diharapkan penelitian selanjutnya melakukan penelitian di lingkup yang lebih luas dari penelitian ini.

\section{REFERENSI}

Berger, Allen and Gregory F Udell. 1998. The Economics Of Small Business Finance: The Roles of Private Equity and Debt Markets in the Financial Growth Cycle, Journal of Banking and Finance. Volume 22

Diamond, Douglas W. 1984. The Society for Economic Analysis Limited: Financial Intermediation and Delegated Monitoring, The Review of Economic Studies.Vol. 51. Hal 393-414

Hartono. 2008. Teori Portofolio dan Analisis Investasi Edisi Kelima. BPFE. Yogyakarta.

Myers, Stewart C dan Nicholas S Majluf, 1984, Corporate financing and investment decisions when firms have information that investors do not have, Journal Of Financial Economics 13, 187-221. 
Nicholls, \& hollmes dalam Nirmala. 2011. Skala Usaha Meningkatkan Profi Usaha Kecil. Fakultas Ekonomi Universitas Gadjah Mada.Yogyakarta

Ross, Stephen. 1977. The determination of financial structure : The incentive signalling approach, Bell Journal of Economics8, 23-40.

Stiglitz, J., A. Weiss, 1981, Credit rationing in markets with imperfect information, American Economic Review 71, 393-410.

Suhardjono, 2003. Manajemen Perkreditan Usaha Kecil dan Menengah, UPP-AMP YKPN Yogyakarta. Tohar, M. 2001.Membuka Usaha Kecil. Yogyakarta: Kanisius

Wicaksono. (2011). Pengaruh Modal Awal, Lama Usaha, Dan Jam Kerja Terhadap Pendapatan Pedagang Kios Di Pasar Bintoro Demak. Universitas Diponegoro : Semarang 